\title{
Using Debit Cards for Incentive Payments: Experiences of a Weekly Survey Study
}

\author{
Heather H Gatney ${ }^{1}$, Mick P Couper ${ }^{1}$, William G Axinn1, Jennifer S Barber ${ }^{1}$ \\ 1 University of Michigan \\ Keywords: survey practice
}

https://doi.org/10.29115/SP-2009-0034

Survey Practice

Vol. 2, Issue 7, 2009

Using Debit Cards for Incentive Payments: Experiences of a Weekly Survey Study

The effectiveness of incentives is well-documented in the literature (e.g., Church 1993; Singer 2002). Cash incentives are both cost-effective and easy to deliver in face-to-face surveys, or as prepaid incentives enclosed with advance letters. For larger amounts-typically used with conditional incentives-checks are often used. The cost of processing and mailing a check can be relatively expensive, especially for small incentive amounts delivered frequently. In online panels, the use of lotteries or rewards points is common, in part because of the cost of delivering repeated incentives of small value (Göritz 2006). Unfortunately these incentives are often less effective than cash.

We describe an alternative approach to incentive delivery, using automated prepaid debit cards or cash gift cards, in the context of a weekly survey with small incentive payments. While ATM or debit cards have previously been used for one-time payment of incentives (e.g., Beckler and Ott 2006; McGrath 2006) and convenience store debit cards have been used for repeated incentive payments among volunteers (Wiebe et al. 2008), we are aware of no other studies that have used this approach for repeated delivery of small incentive amounts in a survey setting. This approach has several important advantages, including reducing the cost of incentive delivery, reducing the administrative costs associated with the need to reconcile cash payments, the automation of the delivery process, and the ability to track card use.

\section{The Relationship Dynamics and Social Life Study}

The Relationship Dynamics and Social Life study (RDSL), known to respondents as the Michigan Study of Young Women (MSYW), is designed to measure the prevalence and correlates of unintended pregnancy during the transition to adulthood. To accomplish this, the study collects dynamic measures of pregnancies, pregnancy intentions, attitudes, and behaviors in a weekly mixed mode (Internet and phone) survey. A representative sample of 1,200 18-and 19-year old women in a selected county in Michigan was enrolled in the study, which began with a 60-minute face-to-face baseline interview, for which they were given a $\$ 35$ incentive. After the interview, women were introduced to the weekly survey and asked to complete the survey on either the Internet or the phone each week for a period of 2.5 years. An incentive of $\$ 5$ 
was offered for each of the rst 4 surveys to encourage enrollment and initial participation. Respondents were offered $\$ 1$ for each subsequent survey, and if 5 consecutive surveys were completed on time, a $\$ 5$ bonus was provided. Over the course of 2.5 years, respondents could earn up to $\$ 271$.

\section{Alternative incentive distribution methods}

We considered a number of alternative methods of incentive distribution before settling on the prepaid debit cards. For example, many interviewer administered surveys compensate respondents in cash immediately following the survey. This method of incentive distribution was used for the baseline interview, but it could not be used for the self-administered weekly surveys. Similarly, mailing cash or checks to respondents on a weekly basis was considered and rejected, given the cost and logistics involved. For example, using First Class postage rates at the time the study was launched, the total cost of postage alone for mailing weekly incentives to 1,200 respondents would be almost $\$ 64,000$, not to mention the cost of processing so many checks (see Table 1). The costs of envelopes, printing, and staff to prepare the mailings would add further costs.

Another alternative we considered was paying respondents on a monthly, quarterly, or even annual basis. While this would have reduced costs associated with processing and mailing checks, this approach would likely be less effective for this cohort. Alternative forms of incentives such as mp3 music les, cellular phone ring tones, and downloadable coupons to local merchants were also considered for their ability to provide an immediate form of payment, but ruled out as they would work for Internet respondents but not phone respondents, and because they may not be equally valued by all respondents. PayPal was rejected for similar reasons.

\section{Reloadable Cash Gift Cards}

We ultimately decided to distribute the weekly survey incentives using a reloadable MasterCard ${ }^{\circledR}$ gift card or debit card to pay the incentives in a secure, cost effective, and timely manner. Although not the same as cash, the cards are a close substitute, as they are accepted by all merchants that accept MasterCard ${ }^{\circledR}$ as a form of payment (including online merchants).

The cards were introduced to respondents at the baseline interview when enrollment into the weekly survey data collection occurred. Respondents who agreed to participate in the weekly surveys completed a "practice" Internet or phone survey at the baseline interview. This survey collected information that was used to order the cards, including name, address, and the last 4 digits of the respondent's social security number. This information was stored in a database which was downloaded each business day by study staff and submitted to the bank issuing the cards. Cards were mailed directly from the bank to the respondents within 10 business days. 


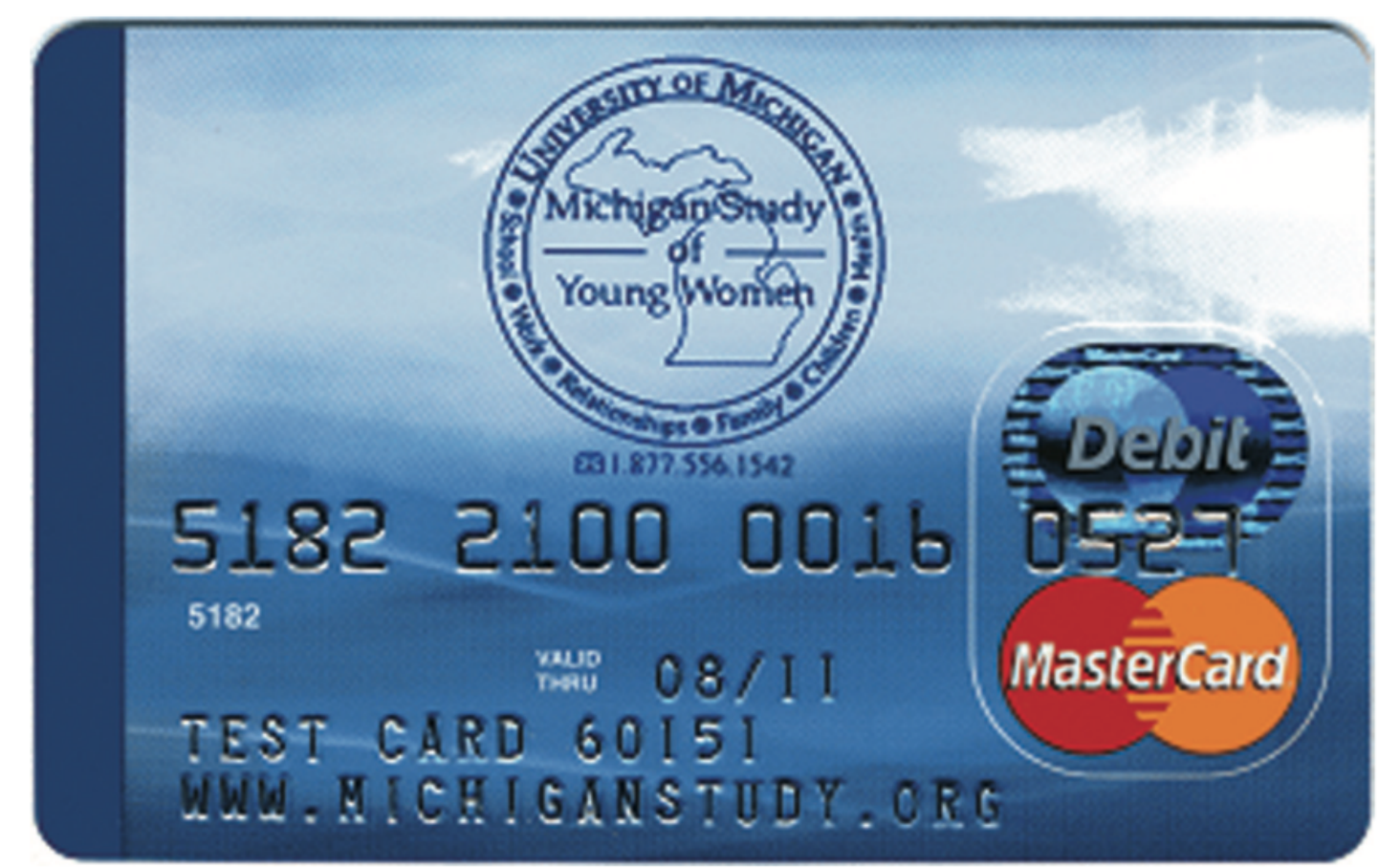

Figure 1 MSYW Cash Gift Card

Secure: The cards were mailed to respondents in plain, white envelopes and required activation before they could be used. Respondents called a toll-free customer service number and entered the last four digits of their social security number to activate the cards.

Like any credit card, the respondent's name was embossed on the front of the card and there was a signature area on the back. A signature was required to make a purchase and purchases could only be made in an amount equal or less than the balance on the card. A respondent was responsible for any purchases made on a card until the card was reported lost or stolen. The customer service number could be called 24/7 to report a card lost or stolen, or also to check the balance and transaction history.

After one full year of using the cards, we have had no reports of fraudulent use. Some of the respondents did have trouble remembering the last four digits of their social security number at the practice survey. When this occurred, interviewers explained to respondents that any 4 digits could be entered, but they also must be remembered later to activate the cards. Only 11 respondents needed staff assistance later to activate the cards.

The direct mailing of the cards from the bank to the respondents produced some problems. We had 35 reports from respondents of never receiving the cards in the mail, either because the respondent provided an insuf cient address or the bank entered the incorrect address into their card order system. It is also possible that the plain white envelopes used for mailing the cards may be mistaken for junk mail and thrown away by respondents. 
Table 1 Per-respondent cost of cards versus checks in the RDSL study.

\begin{tabular}{lll} 
& Card & Check \\
Card purchase & $\$ 1.50+\$ .50=\$ 2.00$ & - \\
Maintenance fee & $\$ 1.00 \times 30$ months $=\$ 30.00$ & - \\
Weekly processing fee & $\$ 0.14 \times 130$ weeks $=\$ 18.20$ & $\$ 0.20 \times 130$ weeks $=\$ 26.00$ \\
Mailing costs (estimated) & - & $\$ 0.85 \times 130$ weeks $=\$ 110.50$ \\
Total per-respondent costs & $\$ 50.20$ & $\$ 136.50$ \\
\hline
\end{tabular}

Cost Effective: The cards cost $\$ 1.50$ each and we chose to pay an additional $\$ .50$ to have the study logo printed on the cards. In addition, there was a $\$ 1$ per card monthly maintenance fee and each time funds were loaded on the cards a $\$ .14$ charge incurred. If a respondent never received a card, there was no additional charge to issue another card. All of these charges were paid by the study. If a card was activated and subsequently reported lost or stolen, a $\$ 10$ fee was charged for the replacement card and transfer of funds to the new card. We decided to reimburse respondents for the rst lost or stolen card and after more than one year using the cards only 30 respondents have reported cards lost or stolen.

For a fee deducted from the card balance, the cards could also have been used to withdraw cash from an ATM. We chose to disable this feature as it was too dif cult to communicate to respondents the potential fees they may be charged and the minimum balances required by various banks to use their ATMs.

Timely: Payments for surveys completed were credited to cards within a couple of days. Survey payment information was stored in a database which was downloaded and submitted to the bank each business day by study staff. Funds were transferred to the cards on the following business day. Thus, surveys completed on a Friday usually would have the money transferred the following Tuesday, while surveys competed on a Monday would have the money transferred on Wednesday. After using the cards for over a year, we experienced no technical problems in the submission of data to the bank and the transfer of funds.

\section{Conclusion}

We have found reloadable cash gift cards to provide a secure, cost effective, and timely method for distributing incentives in a panel study with frequent, remote measurement. The RDSL study administers Internet and phone surveys to the same respondents on a weekly basis for 2.5 years. For us, no other incentive delivery method would work with this design. Whether these advantages apply equally to other types of study design may depend on a number of factors. However, this approach provides a cost-effective and ef cient alternative to traditional incentive delivery approaches. 


\section{REFERENCES}

Beckler, D., and K. Ott. 2006. "Indirect Monetary Incentives with a Complex Agricultural Establishment Survey.” In Proceedings of the Survey Research Methods Section, 2741-48. Alexandria, VA: American Statistical Association.

Church, A. 1993. "Estimating the Effect of Incentives on Mail Survey Response Rates: A MetaAnalysis.” Public Opinion Quarterly 57 (1): 62-79.

Göritz, A. 2006. "Incentives in Web Studies: Methodological Issues and a Review.” International Journal of Internet Science 1 (1): 58-70.

McGrath, D. 2006. "An Incentives Experiment in the U.S. Consumer Expenditure Quarterly Survey." In Proceedings of the Survey Research Methods Section, 3411-18. Alexandria, VA: American Statistical Association.

Singer, E. 2002. "The Use of Incentives to Reduce Nonresponse in Household Surveys." In Survey Nonresponse, edited by R. Groves, D. Dillman, J. Eltinge, and R. Little, 163-77. New York: Wiley.

Wiebe, Douglas J, Brendan G Carr, Elizabeth M Datner, Michael R Elliott, and Therese S Richmond. 2008. "Feasibility of an Automated Telephone Survey to Enable Prospective Monitoring of Subjects Whose Confidentiality Is Paramount: A Four-Week Cohort Study of Partner Violence Recurrence after Emergency Department Discharge." Epidemiologic Perspectives E' Innovations 5 (1): 1. https://epi-perspectives.biomedcentral.com/articles/10.1186/1742-5573-5-1. 